TITLE:

\title{
A New Compound in Au-Pb Alloy System
}

$\operatorname{AUTHOR}(S)$ :

Fujiki, Yoshibumi

\section{CITATION:}

Fujiki, Yoshibumi. A New Compound in Au-Pb Alloy System. Memoirs of the College of Science, University of Kyoto. Series A 1959, 29(2): 197-204

\section{ISSUE DATE:}

1959-09

URL:

http://hdl.handle.net/2433/257429

RIGHT: 


\title{
A NEW COMPOUND IN Au-Pb ALLOY SYSTEM*
}

\author{
BY \\ Yoshibumi FUJIKI** \\ (Received March 1, 1959)
}

\begin{abstract}
A new phase as observed by the electron diffraction method in the thin films of $\mathrm{Au}-\mathrm{Pb}$ alloy was confirmed by both the metallographic and $\mathrm{X}$-ray diffraction methods with bulk specimens. This new phase was an intermetallic compound whose composition was $\mathrm{AuPb}_{3}$, and was formed peritectically like the compounds $\mathrm{Au}_{2} \mathrm{~Pb}$ and $\mathrm{AuPb}_{2}$. The unit cell of $\mathrm{AuPb}_{3}$ is tetragonal with lattice constants $a=11.958 \AA$ and $c=5.878 \AA ⿱$. The measured density is $12.8 \mathrm{~g} \mathrm{~cm}^{-3}$ which agrees well with the calculated one on the basis of 8 molecules per unit cell $\left(12.93 \mathrm{~g} \mathrm{~cm}^{-3}\right)$. The peritectic point of this phase is very close to the eutectic temperature $\left(215^{\circ} \mathrm{C}\right)$.
\end{abstract}

\section{Introduction}

In $\mathrm{Au}-\mathrm{Pb}$ alloy system, two intermetallic compounds, $\mathrm{Au}_{2} \mathrm{~Pb}$ and $\mathrm{AuPb}_{2}$, have already been known. The former is cubic with lattice constant $a=7.93 \AA$, while the latter is tetragonal with $a=7.31 \AA, c=5.644 \AA$, and both crystallize by the peritectic reaction.

By the electron diffraction study on $\mathrm{Au}-\mathrm{Pb}$ alloy films prepared by the deposition of metal vapours in vacuum, the writer found a new phase (Fig. 1) in $\mathrm{Pb}$-rich side of this alloy system, and its composition was estimated between the eutectic (15 wt. $\% \mathrm{Au})$ and $\mathrm{AuPb}_{2}(32.2$ wt. $\% \mathrm{Au})$. This new phase seemed to be stable but not metastable one. In order to confirm this and to determine the accurate composition and the lattice dimensions, the writer carried out the $\mathrm{X}$-ray diffraction and metallographic investigations with bulk specimens.

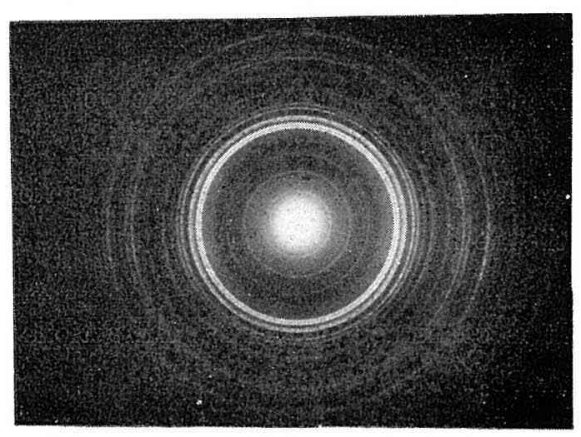

Fig. 1. The electron diffraction pattern of the new phase.

* Communicated by Professor K. Tanaka.

** Institute of Physics, Kyoto Prefectural Medical College. 


\section{Experimental procedure}

Specimens used are $99.99 \% \mathrm{Au}$ and Merck's $\mathrm{Pb}$. Specimens were vacuum sealed in Terex glass tubes $(6 \sim 8 \mathrm{~mm}$ in diameter and about $1 \mathrm{~mm}$ in wall thickness). The amount of specimen in each tube was about $10 \mathrm{~g}$. These specimens were melted in a salt bath at about $400^{\circ} \mathrm{C}$ for $15 \sim 30$ minutes, quenched in a mixture of ice and $\mathrm{NaCl}$ or air-cooled to room temperatures, and then annealed for a suitable time at about $200^{\circ} \mathrm{C}$. After these heat treatments, specimens were polished by emery papers, tooth-paste and silk velvet, etched in the solution of $5 \%$ nitric acid in absolute alcohol and then investigated microscopically.

A part of each especimen used in the microscopical study was examined by the $\mathrm{X}$-ray diffraction with powder method using a $\mathrm{Cu} \mathrm{K}_{a}$ radiation with $\mathrm{Ni}$ filter.

\section{Experimental results}

\section{(a) Determination of composition}

Fig. 2 shows a photomicrograph of the typical eutectic structure obtained by the air-cooled specimen of an alloy containing $15 \mathrm{wt}$. $06 \mathrm{Au}$. This specimen does not show any appreciable change of texture after annealing for about 24 hours at about $200^{\circ} \mathrm{C}$. An $\mathrm{X}$-ray powder pattern obtained by this specimen showed the presence of $\mathrm{Pb}$ and the new phase, thus indicating that the latter is surely present in bulk specimens and its composition is between $\mathrm{AuPb}_{2}$ and the eutectic. Then, starting from the eutectic composition, specimens differing by one or two wt. $96 \mathrm{Au}$ were prepared and examined microscopically as well as by $\mathrm{X}$-ray diffraction method after heat treatment.

Specimens in the range of compositions of $17 \sim 23 \mathrm{wt}$. \% Au indicate two phases of the eutectic and the new phase, one of the photomicrographs being shown in Fig. 3. From the facts that the $\mathrm{X}$-ray patterns of these specimens show very intense diffraction rings of the new phase, it is known that the large grains appeared in Fig. 3 are the crystals of the new phase.

The specimens containing 24 wt. $\%$ Au show one phase after suitable annealing, as is shown in Fig. 4. X-ray pattern of this annealed specimen also shows that of the new phase only (Fig. 9).

The alloy containing $25 \mathrm{wt}$. 9 ' Au shows two phases after annealing (see Fig. 5). It is confirmed by X-ray diffraction that these two phases are the new phase and $\mathrm{AuPb}_{2}$.

From the results mentioned above, it seems that this new phase has no appreciable homogeneous range but is a compound like $\mathrm{Au}_{2} \mathrm{~Pb}$ or $\mathrm{AuPb}_{2}$, and this result should be compared with a calculated value of $24.08 \mathrm{wt} . \% \mathrm{Au}$ for the formula unit $\mathrm{AuPb}_{3}$.

(b) Crystal system and unit cell dimensions

The X-ray diffraction pattern of this new compound (Fig. 9) can be indexed on 
Table I.

\begin{tabular}{|c|c|c|c|}
\hline$(h k l)$ & $d$ (calc.) & $d$ (obs.) & $I$ (obs.) \\
\hline (110) & $8.456 \AA$ & $(8.46 \AA) *$ & $\mathrm{w}$ \\
\hline$(200)$ & 5.979 & $(5.92)^{*}$ & vw \\
\hline (101) & 5.275 & $(5.29)^{*}$ & $w$ \\
\hline$(220)$ & 4.224 & $(4.22)^{*}$ & vw \\
\hline (211) & 3.956 & $(3.96)^{*}$ & $\mathrm{w}$ \\
\hline$(310)$ & 3.781 & $(3.78)^{*}$ & vw \\
\hline (301) & 3.299 & $(3.30)^{*}$ & vw \\
\hline$(002)$ & 2.939 & $(2.98)^{*}$ & vvw \\
\hline (321) & 2.888 & 2.890 & $\mathrm{~s}$ \\
\hline$(330)$ & 2.818 & 2.822 & vs \\
\hline (112) & 2.776 & 2.781 & $\mathrm{~m}$ \\
\hline$(420)$ & 2.674 & 2.672 & $\mathrm{w}$ \\
\hline (411) & 2.600 & 2.597 & vs \\
\hline$(222)$ & 2.413 & 2.418 & $\mathrm{~s}$ \\
\hline$(510)$ & 2.345 & 2.338 & $\mathrm{~m}$ \\
\hline$(312)$ & 2.321 & 2.314 & $\mathrm{~m}$ \\
\hline$(520)$ & 2.221 & 2.227 & vw \\
\hline (402) & 2.096 & 2.098 & vvw \\
\hline (521) & 2.077 & 2.075 & vw \\
\hline (611) & 1.864 & 1.863 & $\mathrm{~m}$ \\
\hline$(710)$ & 1.691 & 1.691 & $\mathrm{~s}$ \\
\hline$(602)$ & 1.650 & 1.651 & $\mathrm{w}$ \\
\hline (711) & 1.625 & 1.628 & $\mathrm{~s}$ \\
\hline$(721)$ & 1.582 & 1.584 & $\mathrm{w}$ \\
\hline$(542)$ & 1.576 & 1.574 & $\mathrm{vw}$ \\
\hline$(650)$ & 1.531 & 1.533 & $\mathrm{vw}$ \\
\hline (731) & 1.517 & 1.519 & vw \\
\hline$(004,523)$ & 1.469 & 1.470 & $s$ \\
\hline$(741,811)$ & 1.438 & 1.438 & $\mathrm{~m}$ \\
\hline $\begin{array}{l}(660) \\
(821)\end{array}$ & $\left.\begin{array}{l}1.409 \\
1.408\end{array}\right\}$ & 1.408 & vvw \\
\hline$(613,224)$ & 1.388 & 1.388 & $\mathrm{w}$ \\
\hline (831) & 1.362 & 1.361 & $\mathrm{w}$ \\
\hline$(840)$ & 1.337 & 1.335 & vw \\
\hline$(910)$ & 1.321 & 1.320 & vVw \\
\hline (414) & 1.311 & 1.307 & $\mathrm{w}$ \\
\hline (901) & 1.296 & 1.293 & $\mathrm{~m}$ \\
\hline$(921,761)$ & 1.267 & 1.265 & vw \\
\hline$(504,434)$ & 1.252 & 1.249 & vvw \\
\hline$(851)$ & 1.239 & 1.240 & vw \\
\hline$(444,653)$ & 1.206 & 1.205 & $\mathrm{w}$ \\
\hline$(771)$ & 1.184 & 1.183 & $\mathrm{w}$ \\
\hline$(852,115)$ & 1.164 & 1.164 & vVW \\
\hline (951) & 1.140 & 1.139 & vw \\
\hline$(704)$ & 1.112 & 1.114 & $\mathrm{w}$ \\
\hline$(724,913)$ & 1.095 & 1.095 & $\mathrm{w}$ \\
\hline$(844,10.33)$ & 0.988 & $0.988_{8}$ & vvw \\
\hline$(981,12.11)$ & 0.977 & $0.979_{2}$ & vvw \\
\hline$(854)$ & 0.959 & $0.959_{8}$ & vvw \\
\hline$(226,12.31)$ & 0.953 & $0.954_{0}$ & vvw \\
\hline$(406)$ & 0.931 & $0.930_{9}$ & vvw \\
\hline$(805)$ & 0.923 & $0.924_{0}$ & vvw \\
\hline
\end{tabular}

* These lines were observed by the electron diffraction method. 
the basis of a tetragonal unit cell with $a=11.958 \AA$ and $c=5.878 \AA$. The observed and calculated spacings are shown in Table $\mathrm{I}$. (The X-ray diffraction rings corresponding to large spacings were difficult to measure, and therefore the values of these spacings were taken from the electron diffraction data.)

The density of $\mathrm{AuPb}_{3}$ measured by Yoshida and Takei's method (1) was found to be $12.8 \mathrm{~g} \mathrm{~cm}^{-3}$ which agrees well with the value $12.93 \mathrm{~g} \mathrm{~cm}^{-3}$ calculated on the basis that the unit cell contains 8 molecules.

\section{(c) Transformation by the peritectic reaction}

Fig. 6 shows a microphotograph of quenched specimen containing 24. wt. \% Au. This shows only two phases. $\mathrm{X}$-ray pattern of this specimen shows the diffraction rings of $\mathrm{AuPb}_{2}, \mathrm{AuPb}_{3}$ and $\mathrm{Pb}$, and the relative intensity of $\mathrm{AuPb}_{3}$ and $\mathrm{Pb}$ is similar to that of eutectic. This shows that these two phases are $\mathrm{AuPb}_{2}$ and eutectic, but not $\mathrm{AuPb}_{3}$ phase. Similar results were obtained for air-cooled specimens of other compositions between 26 wt. $\%$ Au and 17 wt. $\%$ Au.

The quenched specimen of 24 wt. $\%$ Au transforms easily into one phase after the annealing for about 26.5 hours at about $200^{\circ} \mathrm{C}$ (Fig. 4), but the air-cooled one of the same composition (Fig. 7) does not completely transform into one phase even after the prolonged annealing for about 60 hours. (see Fig. 8). These facts and the results mentioned in section (a) show that the $\mathrm{AuPb}_{3}$ phase is formed by the peritectic reaction.

The incompletion of transformation in air-cooled specimens may depend upon the fact that the grain size of $\mathrm{AuPb}_{2}$ is relatively large compared with the grain size of

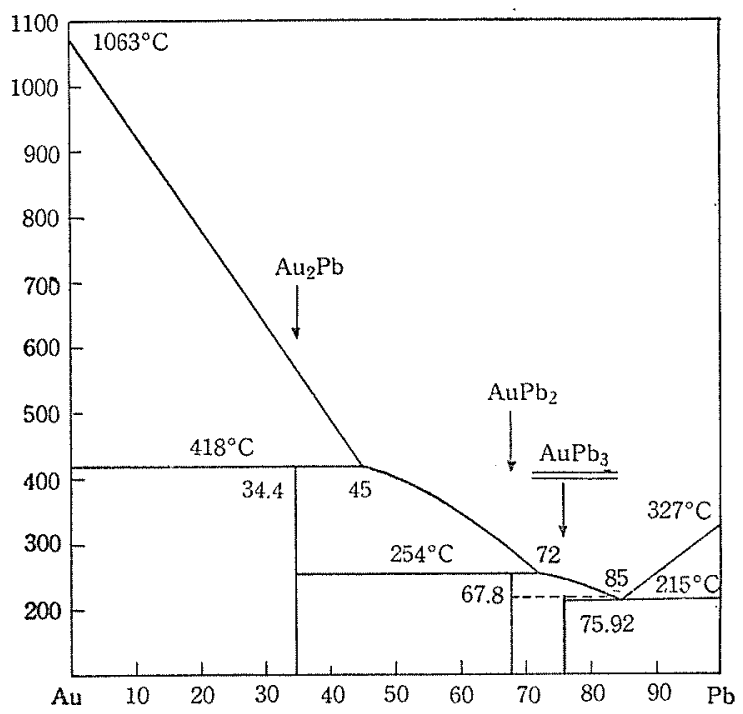

Fig. 10. Phase diagram of $\mathrm{Au}-\mathrm{Pb}$ alloy system. The position of $\mathrm{AuPb}_{3}$ is shown. 
$\mathrm{AuPb}_{2}$ in quenched specimens, and the rate of peritectic reaction is almost interrupted after these grains were surrounded by the new phase.

The fact that the $\mathrm{AuPb}_{2}$ phase presents itself even in the quenched or air-cooled specimens of 17 wt. $\% 0 \mathrm{Au}$ and the $\mathrm{AuPb}_{3}$ phase is absent suggests that the peritectic point of $\mathrm{AuPb}_{3}$ is very close to the eutectic temperature. In fact, the electron diffraction observations on the highest temperature of stability for the $\mathrm{AuPb}_{3}$ phase support this suggestion (Fig. 10), but the precise determination of the peritectic point requires further investigations.

\section{Summary}

In $\mathrm{Au}-\mathrm{Pb}$ alloy system, a new compound was found, the composition of which was metallographically determined to be $\mathrm{AuPb}_{3}$. It was determined by $\mathrm{X}$-ray diffraction method that the unit cell of this compound is tetragonal with lattice constants $a=$ $11.958 \AA$ and $c=5.878 \AA$ containing 8 molecules. The measured density was $12.8 \mathrm{~g} \mathrm{~cm}^{-3}$, while the calculated one was $12.93 \mathrm{~g} \mathrm{~cm}^{-3}$. It was also confirmed by the metallographic study that the new compound $\mathrm{AuPb}_{3}$ is formed peritectically like $\mathrm{Au}_{2} \mathrm{~Pb}$ or $\mathrm{AuPb}_{2}$ and the peritectic point of this compound is very close to the eutectic temperature $\left(215^{\circ} \mathrm{C}\right)$.

\section{Acknowledgements}

The writer wishes to express his gratitude to Prof. K. Tanaka for encouragement and advice in the course of this investigation. He also wishes to thank Prof. $K$. Iwase and Dr. M. Kyōtani for their kind advice and discussions. The writer's thanks are also due to Messrs. R. Suganuma and T. Yoshida for their assistance in this work.

\section{REFERENCE}

1. U. Yoshida and B. TAKeI: Mem. Coll. Sci. Univ. of Kyoto, A15 (1932), 1. 


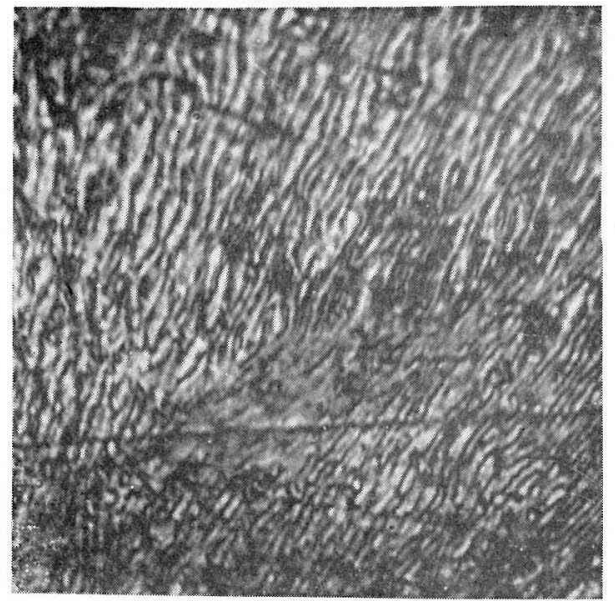

Fig. 2.

15 wt. $\%$ Au, air-cooled (eutectic)

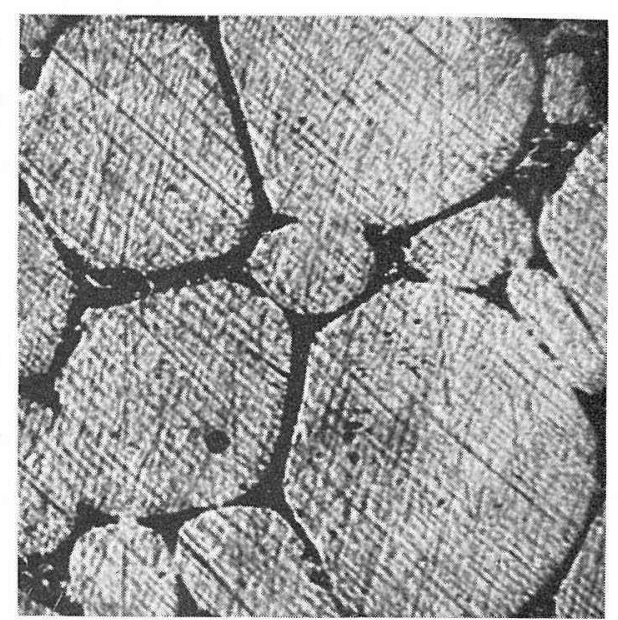

Fig. 3.

$\times 150$

23 wt. $\% \mathrm{Au}$, annealed for 28 hours at $200^{\circ} \mathrm{C}$

$\left(\mathrm{AuPb}_{3}\right.$ +eutectic)

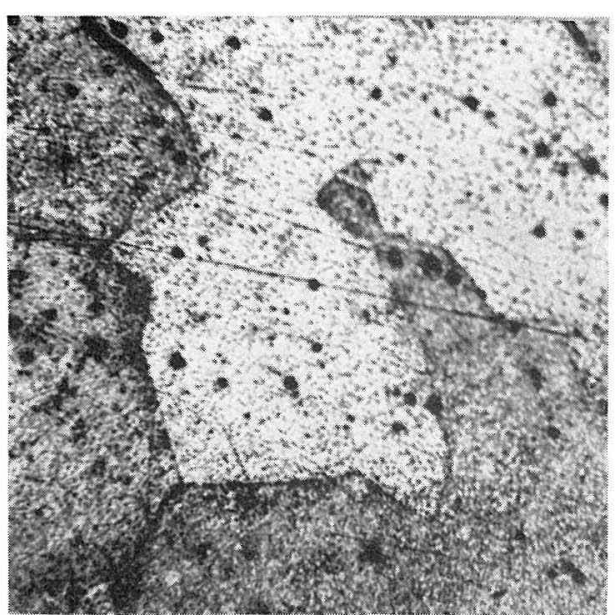

Fig. 4.

$\times 150$

$24 \mathrm{wt} \% \mathrm{Au}$, quenched and annealed for 26.5 hours at $200^{\circ} \mathrm{C}$

$\left(\mathrm{AuPb}_{3}\right)$

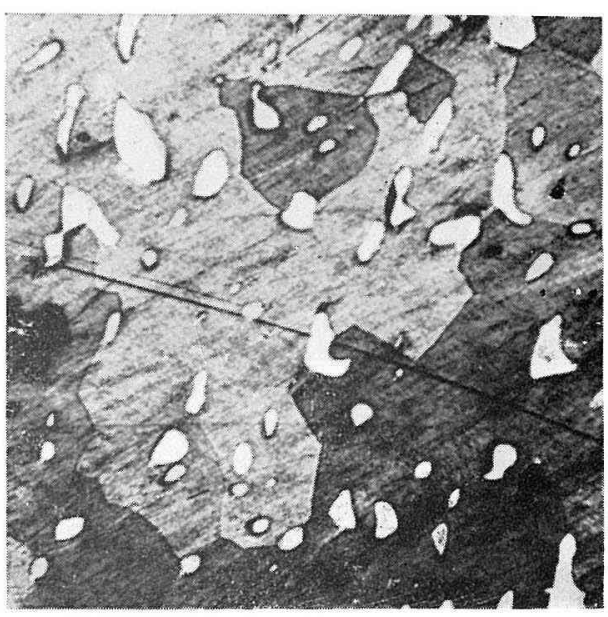

Fig. 5.

$\times 150$

25 wt. $\% \mathrm{Au}$, annealed for 53 hours at $200^{\circ} \mathrm{C}$

$\left(\mathrm{AuPb}_{3}+\mathrm{AuPb}_{2}\right)$ 


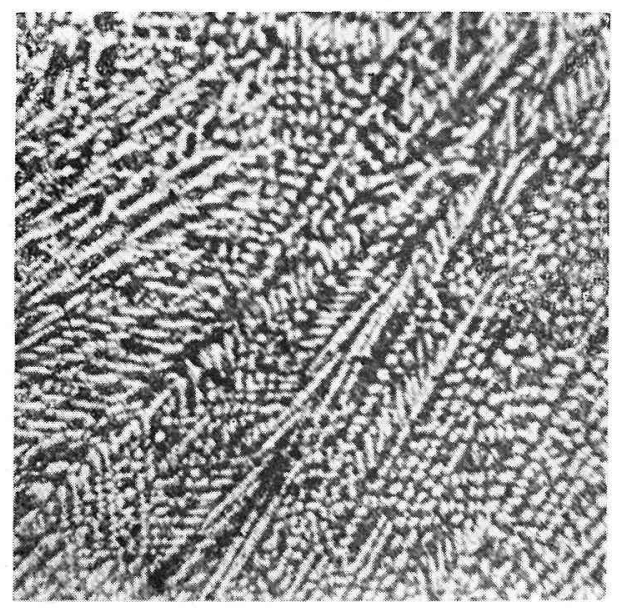

Fig. 6.

$\times 150$

24 wt. $\% \mathrm{Au}$, quenched

( $\mathrm{AuPb}_{2}$ +eutectic)

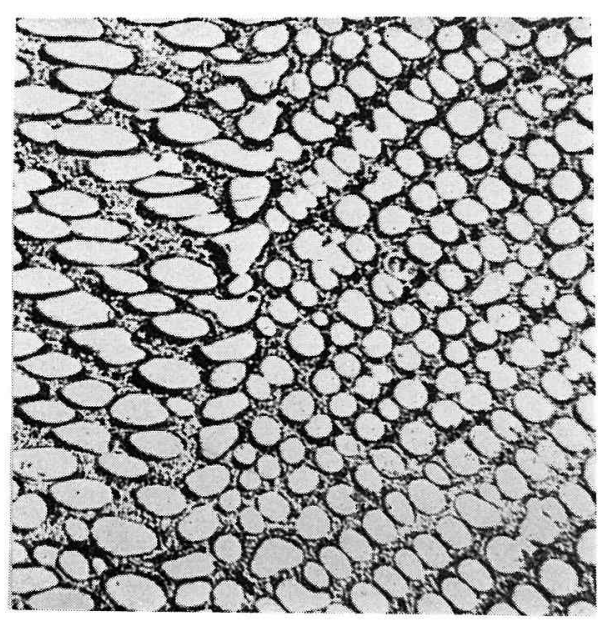

Fig. 7.

24 wt. $\% \mathrm{Au}$, air-cooled ( $\mathrm{AuPb}_{2}$ +eutectic)

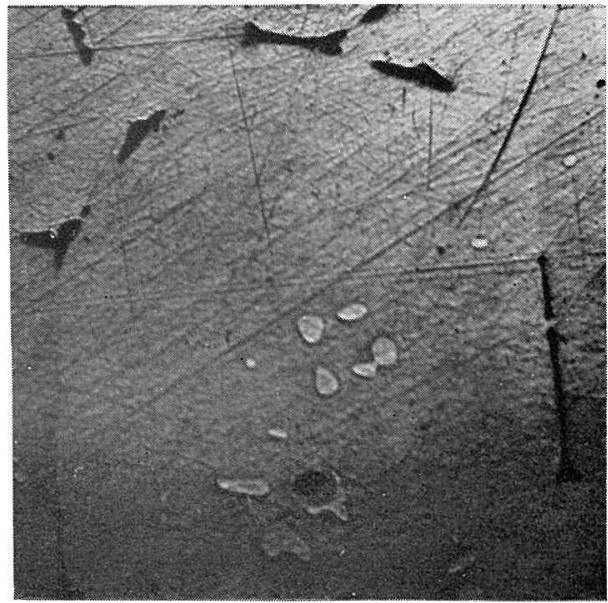

Fig. 8.

$\times 150$

24 wt. $\% \mathrm{Au}$, air-cooled and annealed for 60 hours at $200^{\circ} \mathrm{C}$

$\left(\mathrm{AuPb}_{3}+\mathrm{AuPb}_{2}+\right.$ eutectic) 


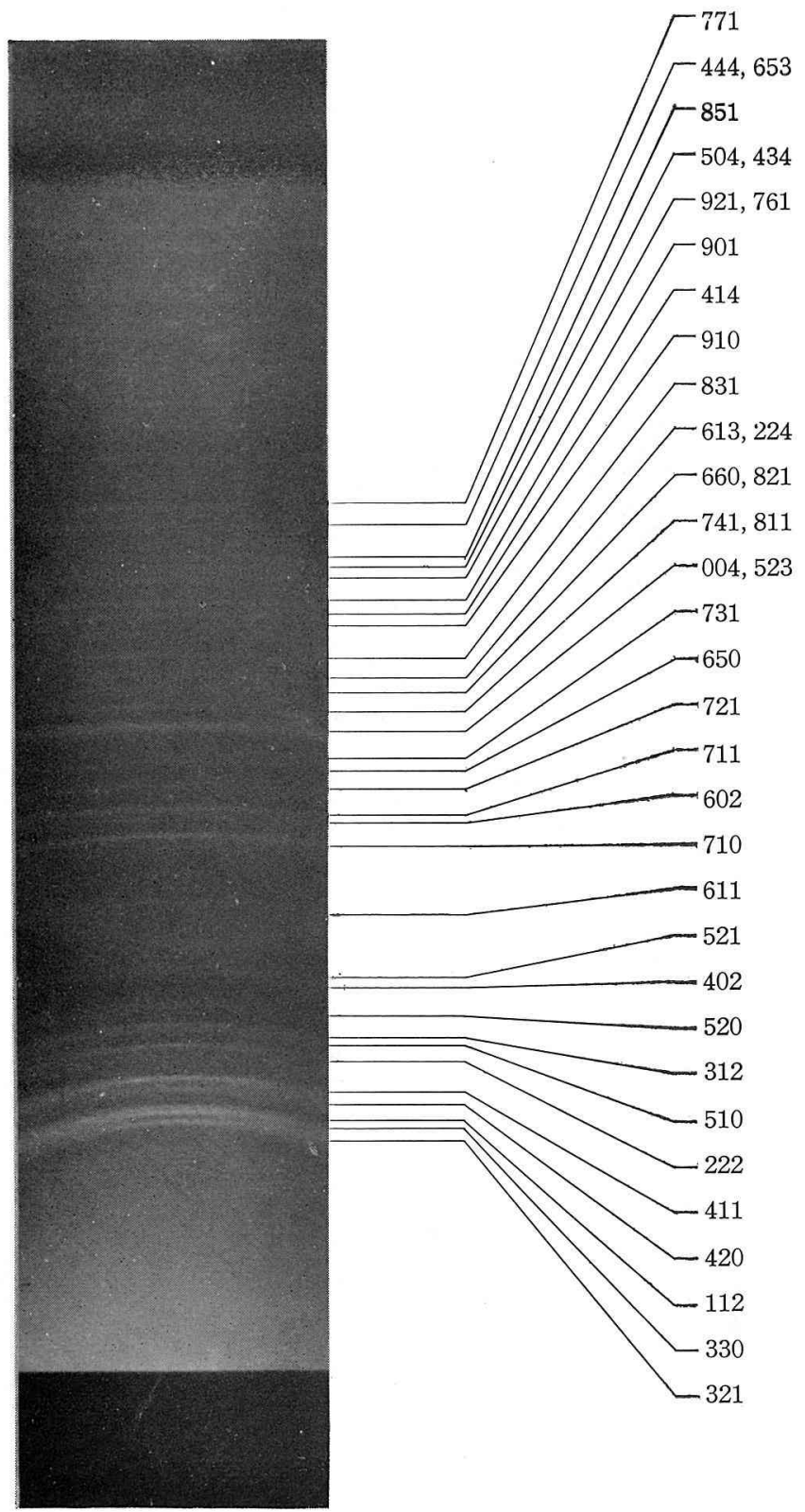

Fig. 9.

24 wt. $\% \mathrm{Au}-\mathrm{Pb} \quad\left(\mathrm{AuPb}_{3}\right)$

Tetragonal $a_{0}=11.95_{8} \AA$ $c_{0}=5.87_{8} \mathrm{~A}$ 